\title{
Conhecimento e Diretrizes curriculares para o curso de Pedagogia no Brasil
}

\author{
Olinda Evangelista*
}

\section{Resumo:}

Trata-se o presente texto de uma reflexão em torno das Diretrizes Curriculares Nacionais para o Curso de Pedagogia (DCNP) que dá nova ordenação ao curso de Pedagogia no Brasil. O objetivo central foi verificar que relações se estabelecem entre formação para a docência - principal função da futura Licenciatura em Pedagogia - e produção de conhecimento, o lugar reservado para a pesquisa nas DCNP e o seu escopo na formação do professor. Para tanto, examinamos dois documentos fundamentais: o Parecer CNE/CP $n^{\circ}$. 5/2005 (BRASIL, 2005) e a Resolução $C N E / C P n^{0} .1 / 2006$ (BRASIL, 2006). Em ambos verificamos a concepção de conhecimento presente e, com base em literatura específica, avançamos uma crítica que evidencia a produção do conhecimento na Licenciatura em Pedagogia como função subalternizada à gestão escolar. A secundarização da pesquisa na formação do Licenciado em Pedagogia concorre para o esvaziamento teórico da área da educação, vinculando-a a uma abordagem fortemente instrumental. Concluímos que, mais do que o abandono da razão, presenciamos o recuo da inteligência nacional em relação à perspectiva histórico-crítica pela adesão a um pensamento gelatinoso, pragmático e relativista. Estamos em presença da proliferação de intelectuais que investem na civilização das elites e catalisa mentes para a crença de que, se não é possível - e talvez nem desejável - mudar o capital, humanizemo-lo.

Palavras-chave: Pedagogia-Currículos. Educação e Estado. Professores-Formação.

\footnotetext{
* Doutora em Educação: História, Política, Sociedade pela Pontifícia Universidade Católica de São Paulo e pós-doutorado em Educação pela Universidade do Minho, Portugal. Membro do Grupo de Estudos sobre Política Educacional e Trabalho - GEPETO (www.gepeto.ced.ufsc.br). Professora Associada II do Centro de Ciências da Educação da Universidade Federal de Santa Catarina. É pesquisadora CNPq.
} 


\section{Introdução}

Em texto publicado em 2005 Eric Hobsbawm refere-se à famosa décima primeira tese marxista sobre Feuerbach - "Os filósofos até agora interpretaram o mundo de maneiras diferentes: trata-se, agora, de transformá-lo" - discutindo o modo pelo qual muitos historiadores abandonaram a explicação causal da história e optaram por abordagens relativistas do real. Pergunta Hobsbawm (2005): “[...] o que houve com o 'interpretar o mundo'?” E responde: é necessária a "reconstrução do front da razão."

Levando em conta o alerta do autor, proponho duas questões para pensarmos no âmbito educacional. A primeira diz respeito ao progressivo abandono da "razão" no âmbito educacional, resultado de abordagens instrumentalistas do conhecimento, de corte pragmático; a segunda refere-se ao fato de que inúmeros intelectuais da área, com rara facilidade, têm aderido a conceitos gelatinosos e difundido concepções afeitas aos mais variados matizes adequacionistas. Tais questões têm sido suscitadas pelos rumos que tomam as políticas públicas de formação do professor no Brasil. ${ }^{1}$

Preocupações relativas à teorização crítica sobre educação nos dias atuais revelam-se espinhosas posto que a área progressivamente tem se afastado de uma reflexão objetiva sobre si mesma e sobre o Brasil (HOSTINS, 2006). De outro lado, a reestruturação produtiva, a perspectiva neoliberal e a idéia de que vivemos o reinado do pensamento único obstaculizam o enfrentamento decisivo deste empobrecimento. Dale (2001) assinala que a existência de uma agenda globalmente estruturada para a educação deixa muitos Estados reféns de políticas internacionais e embora cada nação se aproprie de modo particular dessas orientações o lugar subordinado da América Latina e Caribe na divisão internacional do trabalho não permite superar determinadas imposições, entre as quais se contam a divisão entre países produtores (centrais) e países consumidores (periféricos) de conhecimento, a expansão da rede privada de ensino pelo aumento de suas escolas e pelo avanço sobre a rede pública e a reconversão do preparo do professor e conseqüente aggiornamento de seu trabalho à lógica do mercado.

Segundo Oliveira (2004, p. 1139), 
a constatação de que as mudanças mais recentes na organização escolar apontam para uma maior flexibilidade, tanto nas estruturas curriculares quanto nos processos de avaliação, corrobora a idéia de que estamos diante de novos padrões de organização também do trabalho escolar, exigentes de novo perfil de trabalhadores docentes.

Ademais, o governo brasileiro colabora para o recrudescimento de nossas suspeitas ao tratar os problemas educacionais com excessiva parcimônia. ${ }^{2}$ Demonstrativo disso é a denúncia de Saes (2006, p. 12):

Pode-se hoje, com uma certa dose de tolerância, reconhecer que o direito universal de entrada no sistema escolar está tendencialmente concretizado no Brasil. Inversamente, o maior déficit em matéria de direito à educação consiste na falta de garantias concretas quanto à saída do sistema escolar.

De fato, temos diante de nós um sem número de questões às quais ministros e secretários de educação, além de intelectuais, oferecem uma única resposta: busquemos a qualidade de ensino! Imen (2008, p. 11, grifo nosso) refere-se a essa política na Argentina: En el fondo, continúa como política oficial la ideología de la "calidad educativa" que bien podría traducirse como la "pedagogía de la respuesta correcta."

Esse é o preciso lugar em que nos encontramos quando falamos em Diretrizes Curriculares Nacionais para o Curso de Pedagogia (BRASIL, 2006). ${ }^{3}$ Para elas confluem questões pertinentes à função social da escola, do professor e do conhecimento. O último é o objetivo deste texto em razão do entendimento de que sintetiza tanto o papel da escola na Educação Básica quanto no Ensino Superior cujo elo é o professor. ${ }^{4}$ Importa registrar que a reflexão ora proposta tem a intenção de apenas levantar alguns aspectos para debate.

\section{O Parecer CNE/CP n ${ }^{\circ}$ 5/2005 e as DCNP}

Tendo em vista discutir a idéia de conhecimento no Parecer CNE/ $C P n^{\circ} 5$, de 13 de dezembro de 2005, e na Resolução $C N E / C P n^{\circ} 1$, de 15 
de maio de 2006, que institui Diretrizes Curriculares Nacionais para o Curso de Pedagogia (DCNP) (BRASIL, 2006), algumas passagens foram selecionadas para recuperar brevemente o uso do termo. Comecemos pela referência feita aos anos de 1980 quando, afirma-se, o "movimento de educadores, em busca de um estatuto epistemológico para a Pedagogia" produziu "uma ampla concepção acerca do curso [...] incluída a [...] docência nas séries iniciais do (então) Ensino de $1^{\circ}$ Grau e também na Pré-Escola." (BRASIL, 2005, p. 3). Argumenta-se, no Parecer, que esta orientação é reconhecida pelos sistemas de ensino e pelo alto número de formados e estudantes. Tal reconhecimento teria sido suficiente para tornar o Curso de Pedagogia uma licenciatura estrita tendo na formação para a docência seu objetivo central. Afirma-se também que há interesse de outros licenciados pela gestão de instituições e de sistemas de ensino, em nível pós-graduado, o que levou o "pedagogo" a abrir-se para a docência e os outros docentes para a pedagogia. Parece não restar dúvidas quanto às facetas fundamentais das DCNP: "Pedagogia" significa docência e gestão!

Continua o Parecer (BRASIL, 2005, p. 6):

as DCNP aplicam-se à formação inicial para o exercício da docência na Educação Infantil e nos anos iniciais do Ensino Fundamental, nos cursos de Ensino Médio de modalidade Normal e em cursos de Educação Profissional, na área de serviços e apoio escolar, bem como em outras áreas nas quais sejam previstos conhecimentos pedagógicos. ${ }^{5}$

Nesta primeira "síntese" a produção do conhecimento não é referida, mas evidencia-se o alvo do curso: formar docentes como tarefa central e gestores como tarefa complementar.

No Parecer e nas DCNP conhecimento equivale a "áreas de conhecimento afins" que dão subsídios à formação docente: "o filosófico, o histórico, o antropológico, o ambiental-ecológico, o psicológico, o lingüístico, o sociológico, o político, o econômico, o cultural". Os conhecimentos do campo educacional - pouco esclarecidos - deverão articular-se às "práticas profissionais e de pesquisa", entendendo-se por práticas "o exercício da docência", "o trabalho pedagógico em escolas", "o planejamento", "a coordenação", "a avaliação de práticas educativas em espaços não-escolares" 
e por pesquisa produção de soluções que apóiem as práticas (BRASIL, 2005, p. 6) ${ }^{6}$ Como se percebe, a pesquisa é subordinada à prática, tomada como aplicação das contribuições dos campos de conhecimentos afins. $\mathrm{O}$ estatuto da pesquisa é associado ao "planejamento, execução, avaliação de atividades educativas." (BRASIL, 2005, p. 6), restringindo-se seu escopo.

No que toca aos Princípios do curso, além das competências ${ }^{7}$ que o graduando deve desenvolver, agregam-se "habilidades" descritas como "pluralidade de conhecimentos teóricos e práticos", "interdisciplinaridade, contextualização, democratização, pertinência e relevância social, ética e sensibilidade afetiva e estética" (BRASIL, 2006, Art. $3^{\circ}$ ), constituídas "por meio de múltiplos olhares." (BRASIL, 2005, p. 6). Neste plano afrouxado não é possível saber quem será o licenciado em Pedagogia, posto que o vocabulário que o define não se traduz de forma precisa e coerente. ${ }^{8} \mathrm{~A}$ adesão aparentemente acrítica a um sem número de termos que pecam pela volatilidade ameaça o futuro licenciado de tornar-se uma massa disforme com pinceladas de conhecimentos oriundos da democratização dos olhares sobre aquilo que será sua função: "o conhecimento da escola como uma organização complexa que tem [...] função social e formativa." (BRASIL, 2005 , p. 6) e a tarefa de "promover" a cidadania.?

Sem conhecer em profundidade os "conhecimentos afins", "pensando a escola como organização complexa", portando "múltiplos olhares" e tendo "pluralidade de conhecimentos", o licenciando deverá "propor, realizar, analisar pesquisas" para "a aplicação de resultados" (sic!) tendo em vista

identificar e gerir, em práticas educativas, elementos mantenedores, transformadores, geradores de relações sociais e étnico-raciais que fortalecem ou enfraquecem identidades, reproduzem ou criam novas relações de poder. (BRASIL, 2005, p. 6).

O excerto acima é exemplar da concepção de conhecimento que perpassa o documento: conhecendo-se (?) se pode ser democrático e, portanto, gerenciar - com isenção (?) - a manutenção ou a transformação social e étnico-racial, o fortalecimento ou o enfraquecimento das identidades, a reprodução ou a criação de relações de poder. Em razão desta lógica binária, o Licenciado em Pedagogia poderá pensar que não se trata de conhecer objetivamente a realidade objetiva, mas de escolher entre 
posições ontologicamente equivalentes. Talvez por estarem em posição pouco confortável politicamente, os relatores do Parecer não conseguiram definir exatamente o compromisso principal do Curso de Pedagogia, deixando-o à deriva e ao sabor de interesses que vão ser exibidos como interesses de "cada instituição" de ensino superior e vão permitir a criação de variados modelos de cursos. Esse procedimento elide, concretamente, os litígios em presença não identificáveis com esta ou aquela ala de intelectuais. Se houve uma disputa pelos conceitos "pedagogia", "escola", "docente", "professor", esta não se reduziu apenas, e certamente, aos antagonismos internos à academia. Caberia perguntarmos que projetos históricos de fato estavam em disputa.

A noção de conhecimento subjugada às demandas práticas é perceptível também na seguinte passagem: "os conhecimentos [...] produzidos" devem contribuir para o

periódico redimensionamento das condições em que educadores e educandos participam dos atos pedagógicos [e fornecer] informações para políticas destinadas à Educação Infantil, aos anos iniciais do Ensino Fundamental, bem como à formação de professores e de outros educadores para essas etapas de escolarização. (BRASIL, 2005, p. 7).

Ou seja, o conhecimento a ser produzido pelo licenciado deverá servir ao ato pedagógico e à proposição de políticas educativas sendo desejável sua contenção em tais limites. Evidencia-se, nesta proposição, o caráter fortemente instrumental dessa espécie de conhecimento que, como assinalou Imen (2008), parece comprometer-se com a busca da resposta certa, particularmente se se tratar da produção dos escores necessários à colocação do Brasil no patamar dos países bem sucedidos nas avaliações em larga escala (ZANARDINI, 2008).

Essa perspectiva será reforçada nos Objetivos do Curso de Pedagogia (BRASIL, 2005, p. 7) ao prescrever que as atividades docentes "compreendem participação na organização e gestão de sistemas e instituições de ensino" e que estas englobam, surpreendentemente, "produção e difusão do conhecimento científico-tecnológico do campo educacional, em contextos escolares e não-escolares." (BRASIL, 2005, p. 7-8). Reafirma-se a perspectiva 
de conhecimento adotada: instrumento de compreensão do campo educacional tendo em vista seu adequado gerenciamento seja no nível escolar seja no do sistema de ensino. Por essa razão, a produção de conhecimento figura como item no âmbito da gestão. ${ }^{10}$

Além de ter recebido tarefas hercúleas - como ser "agente de (re) educação das relações sociais e étnico-raciais", entre outras -, o egresso deverá

realizar pesquisas [...] sobre seus alunos e alunas e a realidade sociocultural em que estes desenvolvem suas experiências não-escolares; sobre processos de ensinar e de aprender, em diferentes meios ambiental-ecológicos; sobre propostas curriculares; e sobre a organização do trabalho educativo e práticas pedagógicas [...].

E utilizar, com propriedade, instrumentos próprios para construção de conhecimentos pedagógicos e científicos” (BRASIL, 2005, p. 9). ${ }^{11}$

Pretendendo afirmar a importância da pesquisa na formação do egresso, a Resolução afirma a dependência da produção de conhecimento ao universo escolar e pedagógico e à idéia de que existem conhecimentos pedagógicos e conhecimentos científicos, derivando disso que os conhecimentos pedagógicos não são científicos. Outros exemplos poderiam ser trazidos à baila, mas são suficientes os apresentados para o objetivo em tela. ${ }^{12}$

A guisa de síntese consideremos que o licenciado terá que lidar com o conhecimento sob as seguintes acepções: "áreas do conhecimento" pertinentes ao campo da Pedagogia ou da Educação; "conhecimento multidimensional sobre o ser humano, em situações de aprendizagem"; "conhecimentos aplicáveis em práticas educativas"; "elaboração de conhecimentos"; "articulação do saber acadêmico, da pesquisa, da extensão e da prática educativa"; "áreas de atuação profissional”; "investigação sobre processos educativos e gestoriais"; "elaboração de propostas educacionais consistentes e inovadoras"; "instigador de compromisso social" (BRASIL, 2005, p. 11-13). 
O Curso de Pedagogia, pelo Parecer (BRASIL, 2005) e pela Resolução (BRASIL, 2006), deve prever pesquisas para que os estudantes desenvolvam "postura de investigação científica", pois teria sido consenso entre os participantes na discussão das DCNP, nos últimos anos, a compreensão de que o Pedagogo "é um professor que maneja com familiaridade procedimentos de pesquisa, que interpreta e faz uso de resultados de investigações" propiciando a formação do

profissional que: cuida, educa, administra a aprendizagem, alfabetiza em múltiplas linguagens, estimula e prepara para a continuidade do estudo, participa da gestão escolar, imprime sentido pedagógico a práticas escolares e não-escolares, compartilha os conhecimentos adquiridos em sua prática (BRASIL, 2005, p. 14).

Conquanto se reitere a função da pesquisa na formação, seja sob a forma de iniciação científica ou outras, a produção de conhecimento é sempre referida a um objetivo, explícito ou não, qual seja, o de servir às decisões sobre a prática "docente" e "educativa". Há, de resto, um forte acento sobre a idéia de que os formados devem produzir e construir "novos conhecimentos, que contribuam para a formação de cidadãos, crianças, adolescentes, jovens e adultos brasileiros, participantes e comprometidos com uma sociedade justa, equânime e igualitária." (BRASIL, 2005, p. 14). Desprezada a lógica binária antes usada, pela qual o formando fica face a face com posições a escolher, aqui a eleição não se oferece como possibilidade. Ele formará cidadãos para uma sociedade necessariamente "justa, equânime e igualitária".

Segundo Vieira (2007, p. 113),

pode-se inferir do documento que a proposta para formação do Pedagogo tende a reduzir os aspectos teórico-metodológicos da pesquisa a procedimentos que resultem em soluções rápidas aos problemas que venham a surgir no âmbito restrito da escola, particularmente da sala de aula. 
Cabe chamar aqui as palavras de Moraes (2004, p. 10):

o conhecimento [é] identificado como vocabulário da prática. Não é de espantar, nesta via, o prestígio de uma utopia praticista [...], de modo geral, mas, particularmente no campo da formação e no da prática de professores. A supremacia do saber-fazer, preso aos preconceitos cotidianos, às relações de fácil percepção, desqualifica o esforço teórico associado que foi à perda de tempo e à especulação metafísica. Para o saber-fazer basta a apreensão dos saberes temporais, plurais, heterogêneos, personalizados, situados. Uma atitude que, embora periférica, é eficaz neste nível.

\section{Alguns pontos para reflexão}

$\mathrm{Na}$ rota de levantamento de questões arrolei algumas tendo em vista a composição de um conjunto de problemas que nos dizem respeito e nos dirão futuramente dado o risco presente nas DCNP de dispersão formativa e de esvaziamento da graduação como nível de ensino vocacionado não apenas ao ensino e à extensão, mas à produção de conhecimento.

- Nas DCNP a produção do conhecimento é posta como estratégia de gerenciamento da escola e do sistema de ensino, podendo servir à solução de problemas estritamente educativos ou à proposição de políticas educacionais. Esse viés fortemente pragmático conduz a uma confusa relação entre a formação do intelectual com independência relativamente ao Estado e a formação de um intelectual que tem no Estado um de seus interlocutores privilegiados. ${ }^{13}$ Poder-se-ia perguntar: é possível propor a formação do professor, do gestor e do estudioso sem considerar as determinações históricas que produz cada um deles e o próprio Curso de Pedagogia?

- A produção de conhecimento fica secundarizada porque a Resolução enfatiza a formação do docente e a do gestor. Tudo indica que o Curso configurar-se-á mais como campo de práticas - docentes e de gestão - e menos como campo de teorização sobre a educação, aqui tomado como possibilidades de produção de saber sem que, 
necessariamente, apresentem vinculação direta à prática educativa escolar ou extra-escolar. De outro lado, o acento sobre a formação docente leva a que a formação do pesquisador a ela se sujeite. O complemento "que atua na Educação Básica" à formulação "profissional da educação" restringe o campo de investigação às questões postas pela prática educacional, constrangido ainda por um segundo limite: o de referir-se à educação de crianças de zero a dez anos posto que é a ela que se destinam precipuamente as DCNP. ${ }^{14}$ Não se trata, obviamente, de menosprezar nenhum dos possíveis campos de pesquisa na área educacional. Contrariamente, trata-se de não fechar o campo de possibilidades de intelecção do fenômeno educativo. Podemos indagar se a formação de intelectuais na esfera educativa é algo desejável. É possível delimitar ou definir previamente seu campo de estudo ou seu objeto de investigação, afirmando a prática pedagógica ou, mesmo, a Educação Básica como seu foco privilegiado? Pensar a educação para além da escola não pode ser tarefa apenas de pedagogos e professores, assim como pensar a educação deve ser sua tarefa por excelência.

- Se concordarmos que a produção de conhecimento é secundarizada nas DCNP e que a graduação se configura de modo estritamente profissionalizante e pragmático, a quem caberiam os estudos verticalizados sobre educação? Responder "à pós-graduação" não resolve o problema. ${ }^{15}$ Essa é uma questão diretamente ligada às redes públicas de ensino com as quais o compromisso da formação pedagógica e intelectual do professor deveria ser firmado. Pensar a educação, pensar a escola pública, pensar alternativas educacionais para o país, sem ter o Estado como interlocutor privilegiado, produzir conhecimento sobre o mundo é mais do que assumir compromisso com a escola pública; é assumir uma posição inequívoca de luta contra a sociedade capitalista.

- Se concordamos com Moraes (2001) em sua análise acerca do recuo do pensamento crítico, podemos concluir que o que presenciamos é, claramente, o recuo da inteligência nacional pela adesão a um pensamento gelatinoso, pragmático e relativista. A proliferação de intelectuais que investem na civilização das elites catalisa mentes para a crença de que, se não é possível - e talvez nem desejável mudar o capital, humanizemo-lo. 
Parece oportuno retomarmos as Teses sobre Feuerbach e ficarmos atentos ao que Marx (1977, p. 118-119) afirmou em 1844: “[...] as circunstâncias são modificadas precisamente pelos homens e [...] o próprio educador precisa ser educado." A esse ensinamento Mészáros (2008) agrega outro, igualmente fundamental: é necessário "contra-interiorizar" o capital pela produção de uma "contra-consciência" que nos permita entender o mundo. Segundo Sader (2005, p. 18) Mészáros está dizendo: "entender é desalienar-se, é decifrar, antes de tudo, o mistério da mercadoria, é ir para além do capital."

Em poucas e vitais palavras: é lutar contra "a exploração, a opressão, a dominação e a alienação - isto é, contra o domínio do capital -", tarefa inexoravelmente educacional, ainda que não só.

\section{Notas}

1 Refira-se o recente debate em torno da constituição de um Sistema Nacional Público de Formação dos Profissionais do Magistério, sob a responsabilidade da Coordenação de Aperfeiçoamento de Pessoal de Nível Superior - CAPES, cuja minuta de decreto (BRASIL, 2008) circulou em outubro de 2008. Dada a não finalização desse processo, essas informações não serão aqui discutidas.

2 É o caso dos professores que contam com diferentes instituições Institutos Superiores de Educação, Faculdades, Universidades, Centros Universitários, escolas de ensino médio - e de diferentes níveis - médio e superior - para o seu preparo. Em termos de nível, temos o Curso Normal em nível médio, o Curso Normal em nível superior e as licenciaturas, entre as quais se inclui o Curso de Pedagogia.

3 As questões levantadas neste texto não são novas. Inúmeros são os autores que têm discutido o Curso de Pedagogia. Entre eles cito Saviani (2004); Coimbra (2008); Libâneo [s.d.]; Bissoli Silva (2001); Scheibe e Aguiar (1999); Brzezinski (1999); Oliveira e Resende [s.d.]; Triches (2006); Shiroma e Evangelista (2003, 2004); Pimenta (2002); Freitas (2005); ANFOPE et al. (2005).

4 As DCNP (BRASIL, 2006) geraram e geram discussões que evidenciam seus pontos mais conflituosos: a ênfase sobre a docência e a 
quase omissão do conceito "professor"; a inespecificidade do conceito "pedagogia"; o escasso uso do conceito "pedagogo"; a pouco clara concepção de "escola"; a substituição do especialista pelo "gestor"; a redução do pedagogo ao "docente", entre outros.

5 Art. $2^{\circ}$ As Diretrizes Curriculares para o curso de Pedagogia aplicam-se à formação inicial para o exercício da docência na Educação Infantil e nos anos iniciais do Ensino Fundamental, nos cursos de Ensino Médio, na modalidade Normal, e em cursos de Educação Profissional na área de serviços e apoio escolar, bem como em outras áreas nas quais sejam previstos conhecimentos pedagógicos. (BRASIL, 2006). Art. $4^{\circ} \mathrm{O}$ curso de Licenciatura em Pedagogia destina-se à formação de professores para exercer funções de magistério na Educação Infantil e nos anos iniciais do Ensino Fundamental, nos cursos de Ensino Médio, na modalidade Normal, de Educação Profissional na área de serviços e apoio escolar e em outras áreas nas quais sejam previstos conhecimentos pedagógicos. (BRASIL, 2006).

6 Art. $2^{\mathbf{o}}$ As Diretrizes Curriculares para o curso de Pedagogia aplicam-se à formação inicial para o exercício da docência na Educação Infantil e nos anos iniciais do Ensino Fundamental, nos cursos de Ensino Médio, na modalidade Normal, e em cursos de Educação Profissional na área de serviços e apoio escolar, bem como em outras áreas nas quais sejam previstos conhecimentos pedagógicos. $\$ 2^{\mathbf{o}} \mathrm{O}$ curso de Pedagogia, por meio de estudos teórico-práticos, investigação e reflexão crítica, propiciará: I - o planejamento, execução e avaliação de atividades educativas; II - a aplicação ao campo da educação, de contribuições, entre outras, de conhecimentos como o filosófico, o histórico, o antropológico, o ambiental-ecológico, o psicológico, o lingüístico, o sociológico, o político, o econômico, o cultural. (BRASIL, 2006).

7 Art. $\mathbf{8}^{\mathbf{0}}$, IV - estágio curricular a ser realizado, ao longo do curso, de modo a assegurar aos graduandos experiência de exercício profissional, em ambientes escolares e não-escolares que ampliem e fortaleçam atitudes éticas, conhecimentos e competências [...]. (BRASIL, 2006). Cf., entre outros, Ramos (2002); Dias e Lopes (2003); Campos (2003).

8 Um exemplo de conceito gelatinoso é o de "sociedade majoritária". 
9 Art. $3^{\mathbf{0}} \mathrm{O}$ estudante de Pedagogia trabalhará com um repertório de informações e habilidades composto por pluralidade de conhecimentos teóricos e práticos, cuja consolidação será proporcionada no exercício da profissão, fundamentando-se em princípios de interdisciplinaridade, contextualização, democratização, pertinência e relevância social, ética e sensibilidade afetiva e estética. Parágrafo único. Para a formação do licenciado em Pedagogia é central: I - o conhecimento da escola como organização complexa que tem a função de promover a educação para e na cidadania; [...]. (BRASIL, 2006).

10 Art. $4^{\circ} \mathrm{O}$ curso de Licenciatura em Pedagogia destina-se à formação de professores para exercer funções de magistério na Educação Infantil e nos anos iniciais do Ensino Fundamental, nos cursos de Ensino Médio, na modalidade Normal, de Educação Profissional na área de serviços e apoio escolar e em outras áreas nas quais sejam previstos conhecimentos pedagógicos.

Parágrafo único. As atividades docentes também compreendem participação na organização e gestão de sistemas e instituições de ensino, englobando: I - planejamento, execução, coordenação, acompanhamento e avaliação de tarefas próprias do setor da Educação; II - planejamento, execução, coordenação, acompanhamento e avaliação de projetos e experiências educativas não-escolares; III - produção e difusão do conhecimento científico-tecnológico do campo educacional, em contextos escolares e não-escolares. (BRASIL, 2006).

11 Art. $5^{\circ} \mathrm{O}$ egresso do curso de Pedagogia deverá estar apto a: [...] IX identificar problemas socioculturais e educacionais com postura investigativa, integrativa e propositiva em face de realidades complexas, com vistas a contribuir para superação de exclusões sociais, étnico-raciais, econômicas, culturais, religiosas, políticas e outras; [...] XIV - realizar pesquisas que proporcionem conhecimentos, entre outros: sobre alunos e alunas e a realidade sociocultural em que estes desenvolvem suas experiências não-escolares; sobre processos de ensinar e de aprender, em diferentes meios ambiental-ecológicos; sobre propostas curriculares; e sobre organização do trabalho educativo e práticas pedagógicas; XV utilizar, com propriedade, instrumentos próprios para construção de conhecimentos pedagógicos e científicos; [...]. (BRASIL, 2006). 
12 O Perfil do egresso resultará "do campo teórico-investigativo da educação, do ensino, de aprendizagens e do trabalho pedagógico que se realizam na práxis social" concretizando-se na "docência" entendida como as "atividades pedagógicas inerentes a processos de ensino e de aprendizagens", as "próprias da gestão dos processos educativos em ambientes escolares e não-escolares" e a "produção e disseminação de conhecimentos da área da educação" (BRASIL, 2005, p. 8; BRASIL, 2006, Art. $4^{\circ}$ ).

13 Essa questão foi discutida por Warde (1992) em relação a outro período histórico, mas se adequa perfeitamente ao momento presente.

14 Sobre esse aspecto cf. Küenzer e Rodrigues, 2006.

15 Duarte (2003) discute a formação de intelectuais nos programas de pósgraduação no Brasil e as funções sociais que lhe seriam inerentes.

\section{Referências}

AGUIAR, Márcia A.; SCHEIBE, Leda. Formação de profissionais da educação no Brasil: o curso de pedagogia em questão. Educação \& Sociedade, Campinas, ano 20, n. 68, p. 221-238, dez. 1999.

ASSOCIAÇÃO NACIONAL PELA FORMAÇÃO DOS PROFISSIONAIS DA EDUCAÇÃO. Considerações das entidades nacionais de educação - ANPEd, CEDES, ANFOPE E FORUMDIR: sobre a proposta de resolução do CNE que institui diretrizes curriculares nacionais para o Curso de Pedagogia. Brasília, 2005. Mimeografado.

BRASIL. Conselho Nacional de Educação. Conselho Pleno. Parecer CNE/CP n 05/2005, 13 de dezembro de 2005. Institui Diretrizes Curriculares Nacionais para o curso de graduação em Pedagogia. Encaminhado para homologação do MEC. Brasília, 2005.

BRASIL. Conselho Nacional de Educação. Resolução nº 1, de 15 de maio de 2006. Institui Diretrizes Curriculares Nacionais para o Curso de Graduação em Pedagogia, licenciatura. Brasília, 2006.

BRASIL. Ministério da Educação. Coordenação de Aperfeiçoamento de Pessoal de Nível Superior. Decreto [s/n], de outubro de 2008. Institui o 
Sistema Nacional Público de Formação dos Profissionais do Magistério. Brasilia, 2008. Disponível em: <http://portal.mec.gov.br/arquivos/pdf/ decreto_102008x.pdf>. Acesso em: 30 nov. 2008.

BRZEZINSKI, Iria. Embates na definição da política de formação de professores para a atuação multidisciplinar nos anos iniciais do ensino fundamental: respeito à cidadania ou disputa pelo poder? Educaşão \& Sociedade, Campinas, n. 69, p. 80-108, dez. 1999.

CAMPOS, Roselane F. Do professor reflexivo ao professor competente. In: MORAES, Maria Célia M. de; PACHECO, José A.; EVANGELISTA, Olinda. Formação de Professores: perspectivas educacionais e curriculares. Porto, Portugal: Porto, 2003.

COIMBRA, Camila Lima. O curso de Pedagogia: histórias e debates pós PCNs. In: SIMPÓSIO INTERNACIONAL O ESTADO E AS POLÍTICAS EDUCACIONAIS NO TEMPO PRESENTE, 4., 2008, Uberlândia, MG. Anais... Uberlândia, MG: UFU, 2008.

DALE, Roger. Globalização e educação: demonstrando a existência de uma "cultura educacional mundial comum" ou localizando uma "agenda globalmente estruturada para a educação"? Educação, Sociedade \& Culturas, Porto, n. 16, p. 133-169, 2001.

DIAS, Rosanne E.; LOPES, Alice C. Competências na formação de professores no Brasil: o que (não) há de novo. Educação e Sociedade, Campinas, v. 24, n. 85, p. 1155-1177, set. 2003.

DUARTE, Newton. A pesquisa e a formação de intelectuais críticos na pós-graduação em Educação. Perspectiva, Florianópolis, v. 23, n. 2, p. 89110, jul./dez. 2005.

FREITAS, Helena. Sobre diretrizes e pedagogia. São Paulo, 2005. Artigo não publicado. Texto restrito para estudo da entidade. Disponível em: <http://lite.fae.unicamp.br/anfope>. Acesso em: 13 ago. 2005.

HOBSBAWM, Eric. A crise do capitalismo e a importancia atual de Marx. Entrevistador: Marcello Musto. In: CARTA Maior. Porto Alegre, 2008. Disponível em: < http://www.cartamaior.com.br/templates/ materiaMostrar.cfm?materia_id $=15253 \&$ alterarHomeAtual=1.>. Acesso em: 18 nov. 2008. 
HOBSBAWM, Eric. Em defesa da História. Revista Princípios: Revista Teórica, Política e de Informação, São Paulo, n. 82, capa, 1 dez. 2005. Disponível em: <http://www.vermelho.org.br/museu/principios/ anteriores.asp?edicao $=82 \&$ cod_not $=955$. $>$. Acesso em: 10 ago. de 2008.

HOSTINS, Regina C. L. Formação de pesquisadores na pós-graduação em educação: embates epistemológicos, dimensões ontológicas. 2006. $175 f$. Tese (Doutorado em Educação)- Programa de pós-graduação em Educação, Centro de Ciências da Educação, universidade Federal de Santa Catarina, Florianópolis, 2006.

IMEN, Pablo. Política educativa, trabajo docente y lucha de clases: la cuestión de la autonomía laboral y la democratización de la cultura escolar. In: SEMINÁRIO REDESTRADO: NUEVAS REGULACIONES EN AMÉRICA LATINA, 7., 2008, Buenos Aires. Anais... Buenos Aires: UBA, 2008. CD-ROM. p. 1-21.

KÜENZER, Acácia Z.; RODRIGUES, Marli de F. As diretrizes curriculares para o curso de Pedagogia: uma expressão da epistemologia da prática. In: ANAIS DO XIII ENCONTRO NACIONAL DE DIDÁTICA E PRÁTICA DE ENSINO, 2006, Recife. Novas subjetividades, currículos, docência e questões pedagógicas na perspectiva da inclusão social. Anais... Recife: Bagaço, 2006. p. 185-212.

LIBÂNEO, José C. Diretrizes curriculares da Pedagogia: um adeus à pedagogia e aos pedagogos? In: ANAIS DO XIII ENCONTRO NACIONAL DE DIDÁTICA E PRÁTICA DE ENSINO, 2006, Recife. Novas subjetividades, currículos, docência e questões pedagógicas na perspectiva da inclusão social. Anais... Recife: Bagaço, 2006. p. 213-242.

LOCATELLI, Piero. Haddad anuncia sistema nacional de formação de professores; investimento será de R \$ 1 bi. In: UOL Educação. São Paulo, 2009. Disponível em: <http://educacao.uol.com.br/ ultnot/2008/10/10/ult105u7105.jhtm.>. Acesso em: 10 out. 2008.

MARX, K.; ENGELS, F. Teses sobre Feuerbach. São Paulo: Alfa-Ômega, 1977.

MÉSZÁROS, István. A crise em desdobramento e a relevância de Marx. In: RESISTIR. Info, 2008. Palestra escrita para uma reunião em Conway 
Hall, Londres, a 21 de Outubro de 2008. Disponível em: <http://resistir. info/.>. Acesso em: 18 nov. 2008.

MORAES, Maria Célia M. de. Recuo da teoria: dilemas na pesquisa em educação. Revista Portuguesa de Educação, Braga, PT, ano 14, n. 1, p. 7-25, 2001.

Incertezas nas práticas de formacão e no conbecimento docente.

In: CONGRESSO LUSO-BRASILEIRO DE ESTUDOS

CURRICULARES, 3., 2004, Rio de Janeiro. Rio de Janeiro, 2004.

Texto para a mesa-redonda "Políticas de Formação de Professores".

Mimeografado.

OLIVEIRA, Dalila Andrade. A reestruturação do trabalho docente: precarização e flexibilização. Educação \& Sociedade, Campinas, v. 25, n. 89, p. 1127-1144, set./dez. 2004. Disponível em: <http://www.cedes. unicamp.br.>. Acesso em: 21 ago. 2008.

OLIVEIRA, Marília V. de; RESENDE, Valéria A. D. L. de. Fragmentos da formação e identidade do pedagogo dos anos 60 aos nossos dias. Anais do $\mathrm{V}$ Congresso Luso-brasileiro de História da Educação. Uberlândia, MG: UFU, 17 a 20 de abril de 2006. p. 6383-6396. Disponível em: <http://www.faced. ufu.br/colubhe06/anais/arquivos/577MariliaVilela_e_Valeria.pdf $>$. Acesso em: 23 de jul. 2008.

PIMENTA, Selma Garrido (Org.). Pedagogia e pedagogos: caminhos e perspectivas. São Paulo: Cortez. 2002.

RAMOS, Marise N. A Educação profissional pela pedagogia das competências: para além da superfície dos documentos oficiais. Educacãa \& Sociedade, Campinas, v. 23, n. 80, p. 405-427, set. 2002.

SAES, Décio A. M. de. Obstáculos políticos à concretização do direito à educação no Brasil. Linhas Críticas, Revista da Faculdade de Educação, Brasilia, DF, v. 12, n. 22, p. 23-40, jan.- jun. 2006.

SAVIANI, Dermeval. O espaço acadêmico da pedagogia no Brasil. Perspectiva histórica. Revista Paidéia: Cadernos de Psicologia e Educação, Ribeirão Preto, SP, v. 14, n. 28, p. 113-124, 2004. Disponível em: <http:// sites.ffclrp.usp.br/paideia/artigos/28.htm.>. Acesso em: 25 maio 2008. 
SHIROMA, Eneida O.; EVANGELISTA, Olinda. A colonização da utopia nos discursos sobre profissionalização docente. Perspectiva, Florianópolis, v. 22, n. 2, p. 525-545, jul./dez. 2004.

SHIROMA, Eneida O.; EVANGELISTA, Olinda. Um fantasma ronda o professor: a mística da competência. In: MORAES, Maria Célia Marcondes de (Org). Iluminismo às avessas: produção de conhecimento e políticas de formação docente. Rio de Janeiro, 2003. p. 81-98.

SILVA, Carmem S. Bissoli. Diretrizes curriculares para o curso de Pedagogia no Brasil: um tema vulnerável às investidas ideológicas. In: Anais da $24^{\mathrm{a}}$ Reunião da ANPEd, Caxambu, 2001. p. 1-17. Disponível em: <www2. uerj.br/ anped11/24/Silva.doc.> . Acesso em: 20 jun. 2008.

TRICHES, Jocemara. Curso de Pedagogia: projetos em disputa. Florianópolis: CED/UFSC, 2006. Relatório Parcial de Pesquisa. PIBIC/ CNPq - BIP/UFSC 2005/2006.

VIEIRA, Suzane da R. Diretrizes curriculares para o curso de Pedagogia: pedagogo, docente ou professor? 2007. 141f. Dissertação (Mestrado em Educação)-Programa de pós-graduação em Educação, Centro de Ciências da Educação, Universidade Federal de Santa Catarina. Florianópolis, 2007.

ZANARDINI, JOÃO BATISTA. Ontologia e avaliação da educação básica no Brasil (1990-2007). 2008. 209f. Tese (Doutorado em Educação)Programa de pós-graduação em Educação, Centro de Ciências da Educação, Universidade Federal de Santa Catarina, Florianópolis, 2008.

WARDE, Mirian Jorge. Pesquisa em educação: entre o Estado e a ciência. In: BRANDÃO, Zaia et al. Universidade e educação. Campinas, SP: Papirus, 1992. (Coletânea CBE). 


\section{Knowledge and Curriculum guidelines for teacher educa- tions courses in Brazil}

\begin{abstract}
:
This paper analyzes the National Curriculum Guidelines for the Pedagogy Course (DCNP) which establishes a new order for teacher education in Brazil. The central objective of this paper is to verify what relations are established between teacher education - the principal function of certification in Pedagogy - and the place reserved for research in the DCNP and its scope in teacher education. To do so, we examined two fundamental documents: the report Parecer CNE/CP $n^{\circ}$. 5/2005 (BRASIL, 2005) and resolution Resolução CNE/CP n. 1/2006 (BRASIL, 2006). In both we found the concept of knowledge present and, based on the specific literature, we present a critique of the production of knowledge in teacher education as a function subaltern to school management. The secondary role of research in the training of certified teachers contributes to the theoretical weakening of the field of education and a strongly instrumental approach. We conclude that, more than an abandonment of reason, we find a stepping back of national intelligence in relation to the historical-cultural perspective and adhesion to a gelatinous, pragmatic and relativist thinking. We find a proliferation of intellectuals who invest in a civilization of elites and catalyze minds from the belief that, if
\end{abstract}

\section{Conocimiento y Directrices para el curso de Pedagogia em Brasil}

\section{Resumen:}

El presente texto aborda una reflexión en torno a las Directrices Curriculares Nacionales para la Carrera de Pedagogía (DCNP) que expresan una nueva reglamentación al curso de Pedagogía en Brasil. El objetivo central fue verificar cuales son las relaciones que se establecen entre la formación para la docencia - principal función del futuro, y el Profesorado en Pedagogía - la producción de conocimiento, el lugar reservado para la investigación en las DCNP y su finalidad en la formación de docentes. Para tal fin, examinamos dos documentos fundamentales: el parecer $\mathrm{CNE} / \mathrm{CP} n^{\circ}$. 5/2005 (BRASIL, 2005) y la Resolución CNE/CP n. 1/2006 (BRASIL, 2006). En los dos documentos constatamos una concepción de conocimiento y con base en la literatura específica, realizamos una crítica que evidencia que la producción de conocimiento en el profesorado en Pedagogía aparece como una función subalterna a la gestión escolar. La secundarización de la investigación en la formación de los docentes en la carrera de Pedagogía converge para un vaciamiento teórico en el área de la educación y está vinculada a un abordaje eminentemente instrumental. Concluimos que, más que el abandono de la razón, presenciamos una "retirada" de la inteligencia nacional en relación a la perspectiva 
it is not possible - and perhaps not desirable - to change capital, it can be humanized.

Key words: Pedagogy Curriculum. Education and State. Teacher Education. histórico-crítica y una adhesión a un pensamiento "gelatinoso", pragmático y relativista. Estamos en presencia de la proliferación de intelectuales que invierten en la civilización de las elites y captan mentes para la creencia de que, al no ser posible - y tal vez no sea deseable - cambiar el proceso del capital, por lo menos, hay que humanizarlo.

Palabras-clave: Pedagogía-Currículo. Educación y Estado. Docentes-Formación.

\section{Olinda Evangelista}

Centro de Ciências da Educação - Departamento de Estudos Especializados em Educação

Universidade Federal de Santa Catarina.

Campus Universitário - Trindade

Florianópolis-SC

CEP: 88040-900

E-mail: olindaevangelista35@hotmail.com

Recebido em: 9/9/2008

Aprovado em: 15/11/2008 